\title{
Introduction to Research Handbook on International Taxation
}

Yariv Brauner

For the first time in a long while, perhaps ever, international tax policy is not only a "hot" topic, but also a topic high on the agenda of most politicians, regardless of origin. The global starvation for revenue that most countries, rich and poor, experienced in the period following the global financial crisis of 2008 coincided with dramatic geopolitical changes and an intensification of internal crises within the international tax regime, triggered mostly by the ascent of globalization and the so-called digital economy. The most notable consequence of these developments was the Base Erosion and Profit Shifting (BEPS) project that had been charged with tackling the various challenges that such developments presented to the international tax regime. During the project (2013-2015), the global political will to reform the regime had peaked, only to wane again once the project transitioned into its most meaningful stage of implementation.

We now all face the true test of reducing the discourse to actual rules that inevitably require difficult compromises and the resolution of dilemmas over the appropriate levels of cooperation and independence retained by the different stakeholders: nation states, international organizations, and multinational enterprises (MNE). This is therefore a perfect time for the publication of the first Research Handbook on International Taxation. This collection aims to capture some of the core challenges faced by the international tax regime, to assess their possible impacts on the regime's various stakeholders, and to evaluate possible paths to reform. All the chapters intend to provide the reader with an initial reading that would be essential for research of the topics discussed, as well as an original point of view that advances the relevant scholarly discourse.

These chapters present a diversity of perspectives and a plurality of approaches to the research of international taxation. Yet, a few salient themes come up strongly from this collection. First, there is a certain robustness to the existing regime and the basic concepts it represents. The regime provides therefore a good basis for needed, future reforms, and a structure and stability that should be used in the quest for progress even when some or many of the old rules and structures are questioned and replaced. This somewhat conservative observation does not have to, and should not, clash with the obvious necessity of fundamental reforms of the international tax regime. The longawaited update should be reconciled therefore with the core basis of understanding and legitimacy that the regime, as such, already enjoys. The second theme coming out of all the chapters of this Handbook is therefore the need for an update and a genuine rethinking of the fundamentals of the regime. There is a need to adjust nineteenth- and twentieth century solutions to the challenges of the twenty-first century; to embrace globalization, the interdependence of the world economies, and the ensuing impossibility of truly unilateral international tax policy; and to accommodate the expanding cast of players on the political map in this post-superpower era, where legitimacy, intricacy, and 
principles are necessary components in any policy work while coercion and boiler-plate, singular norms lose their effectiveness and become a thing of the past. A third theme of this Handbook is the importance of a discussion of the institutional aspects of the international tax regime. Currently a soft-law-based regime, led by the OECD, which is not a legitimate international standard-setter, the expansion and success of the regime as well as the changing circumstances already described beg a question about the need for more formality and the creation of a legitimate forum for international taxation. Different chapters provide different, perhaps even conflicting perspectives on this question; still, all the chapters highlight the inevitability of its discussion.

The Handbook is divided into five parts, representing different facets of international tax research, facets that put together a picture as comprehensive as possible of the academic challenge faced by tax scholars. Part I delves into some of the fundamentals of the regime itself. Chapter 1 by Reuven S. Avi-Yonah examines the nature of the international tax regime as part of international law.

Avi-Yonah specifically examines the extent to which the norms of international taxation qualify as customary (international law). The bilateral, decentralized nature of the international tax regime made it very resilient to fundamental reform, and especially averse to calls for a formalization of the regime into an inevitably multilateral structure. Avi-Yonah demonstrates that regardless of such aversion, some fundamental norms have evolved to dominate the regime to the extent that countries feel obligated to follow them, even in the absence of a formal (bilateral) treaty obligation to that effect.

This controversial claim is central to any debate over the future of the international tax regime, since, if validated, the processes identified by Avi-Yonah may prepare the ground for a future, more centralized, and eventually more formal regime through the evolution of customary law, similarly to other international legal regimes in history. These parallels could also fortify the international tax discourse, which could benefit from the lessons learned by other regimes that have previously gone through similar evolutions. Finally, this Chapter provides us with an opportunity to deeply evaluate some of the norms that Avi-Yonah uses as examples for the evolution of customary international law (permanent establishment and arm's length) and examines the extent to which they have all acquired sufficiently universal meanings.

Sunita Jogarajan, in Chapter 2, takes us from the future to the past, as she tracks the origins of the international tax regime. An authority on the history of the regime, Jogarajan draws parallels between the impetus for the regime's organization in the beginning of the twentieth century and its current reorganization in the twenty-first century (concerns about tax avoidance and tax evasion). Jogarajan further notes the organizational parallels between the two events, the leadership of international organizations in both cases, and the use of mechanisms such as legal transplantation. The relatively recent ascent of historical analysis in the interpretation of international tax norms proves its essential place in any serious tax policy study. This chapter serves as a core building block in this evolution as it sheds light and informs us about the most contemporary developments of the international tax regime.

Chapter 3, by Allison Christians, provides us with an institutional perspective of the recent developments involving the international tax regime, a key issue since the regime is clearly dominated by a single international organization (the OECD) that crafted it to fit its irregular leadership, being an exclusive organization of the richest countries in 
the world and hence not a formal (or legitimate) international standard-setter, through the use of "soft law" and informal governmental networks. Even now, the reign of the OECD has increasingly come under attack, and other international institutions have begun to compete for roles and influence over the evolution of the regime. In her chapter, Christians examines the various governmental and nongovernmental networks competing for influence over the international tax regime, pointing to their faults and benefits, and their contribution to the processes of cooperation and noncooperation in different instances of norm creations. This examination should inform any attempt to reform the regime, especially when institutional changes, such as all proposals for a formalization of the regime, would be on the agenda.

Finally, a core concept of international relations, nondiscrimination, is examined by Elizabeth Adams, Michael Knoll, and Ruth Mason in Chapter 4. This chapter demonstrates the richness of the concept and its high dependence on context. The seemingly straightforward idea of similar treatment breaks down into complex norms with unique impacts in different circumstances explored by the authors in an analysis that sheds light not only on the intricacy of basic, core concepts, such as nondiscrimination, when they are actually put to work in the international context, but also on the doctrine; the rules themselves are viewed in a different light when examined from the perspective of nondiscrimination. Finally, the concept of nondiscrimination in international taxation, being originally borrowed from international economic law, enriches an examination of the international tax regime as a part of international law, with the very unique example of the European Union, which developed the only ultra-national tax regime in place around this concept of nondiscrimination, a test case that has already informed many studies of international taxation and promises to continue and do so increasingly as the international tax regime reinvents itself in the twenty-first century.

Part II of this Handbook provides contemporary perspectives on a few of the key doctrinal building blocks of international taxation. Chapter 5, by Pasquale Pistone, focuses on the taxation of employment income, perhaps the most ubiquitous item of income shared by most taxpayers. Nonetheless, the interpretation of the rather universal rule for taxation of income from employment presents significant challenges since the term employment does not enjoy a universally accepted definition, which prevents any such definition from being written into tax treaties. The need for interpretation of an undefined term made this common norm a ground zero for the debate over the proper interpretation of tax treaties, an unsettled debate that is at the heart of the crystallization of the international tax regime. This chapter is complemented by Chapter 6, by Andrés Báez Moreno, which examines the taxation of services, the most controversial and perhaps most important item of income in this era of globalization. In particular, this chapter explores the scope of the traditional service norms that when originally crafted had clearly not had in mind the advent of remote and internet-based services, for example, and hence are poorly designed for these business activities. Báez Moreno elaborates more specifically on the most significant, perhaps the sole significant innovation in tax treaty law of recent times, embedded in Article 12A of the U.N. Model, which deviates from the normal rules for the taxation of services in the case of technical services. More than any other area examined in this book, this area exposes the differing positions of developed and developing countries and the intensity of their differences, exacerbated and brought to the surface as a consequence of recent developments and particularly of globalization. 
Chapter 7, by Aitor Navarro, analyzes the contemporary laws of transfer pricing, one of the key normative areas of law governing international taxation, the essentially universal arm's length standard, which on the one hand enjoys general acceptance yet on the other hand faces the most criticism and implementation difficulties in the changing circumstances of the twenty-first century. Most importantly, intangibles present a hard case for the market-based valuation standard. Navarro depicts the complexity of the transfer-pricing rules and their inevitability, attempting to expose the most vulnerable seams that keep the regime together yet that threaten to challenge its viability. Finally, Navarro presents a methodological perspective that could be helpful for a pragmatic implementation of the existing rules in a legitimate manner.

Often viewed as one of the most interesting areas of international taxation, Part II's final chapter shares the norms pertaining to sportspersons and entertainers that provide a laboratory to examine general norms through typical exceptions, such as these rules. In Chapter 8, Karolina Tetłak expertly examines the rules of Model Article 17 that provides for source rather than residence taxation for these more mobile, and many times more significant taxpayers. In particular, she examines the supposed simplification element, a force of attraction rule unique to Article 17, and critically challenges its effect and the conventional wisdom over the balance struck between the needs for accuracy and practicality, or ease of administration, (particularly) in the OECD Model's distributive rules. This analysis is very timely when essentially all countries struggle with the attribution of profits to permanent establishment (and the dilemma described between accuracy and practicality) perhaps more than any other norm of international taxation.

Part III includes chapters on a few key debates that inform the most important dilemmas of international tax policy. Tsilly Dagan, in Chapter 9, homes in on the core debate in international taxation. She explains that the binary choice between cooperation and competition is both false and harmful. She explains that in the absence of a centralized authority the international tax regime garners market features, which leads to tax competition that is inherently inefficient and substitutes policy with such market dictates. The obvious response to this constraint is to cooperate. But, Dagan argues, cooperation may not be the right answer because it is itself problematic, especially if used by powerful factors to gain even more power, increasing inefficiency. Dagan concludes that a balance should therefore be struck between competition and cooperation with a view to achieving normative goals for the international tax regime. Overall, this chapter serves to caution against automatic resort to enhanced cooperation in general, and to multilateralization in particular, as reflexive, simplistic responses to the problems presented by tax competition.

Luis Eduardo Schoueri and Ricardo André Galendi Júnior, in Chapter 10, review critically the arm's length standard that dominates the taxation of business worldwide. This essentially universal standard is often contested by ideas that prefer formulary taxation of various types of income, leading to one of the most important debates in international taxation at the present, a debate that is presented as binary while it is clear, and the existing rules similarly reflect that a hybrid of these approaches would likely prevail. This chapter explains that the arm's length standard performs a dual role, allocating both tax burdens and taxing rights (under the assumption of no double taxation). The universality of the standard stems from its intuitive appeal, while the challenges stem from the globalization of the economy and the ascent of intangibles as critical drivers of value. It argues that 
reform of the arm's length standard should consider its dual function, and therefore that the balancing of the functions is difficult, making it unlikely to achieve perfect outcomes from both perspectives. In the absence of such perfect reform, this chapter supports a careful approach that would maintain the intuitive reliance on the arm's length standard.

In Chapter 11, Michael Lang returns to the core question of treaty interpretation and the relationship between domestic and international law in the field of taxation. This chapter explains that interpretation of a legal provision is about finding its meaning, which is determined by taking into account the language, but also the aim and purpose of a provision, the context in which the provision is embedded, and, finally, its history. Lang emphasizes that interpretation of tax treaties should not differ from that of any other legal interpretation. Following this logic, Lang argues that even interpretation rules require interpretation, a controversial issue in tax treaty law since almost all treaties include a provision that permits the resort to domestic law when terms are not defined in the treaty itself (OECD Model Art. 3[2]). Lang argues for a more careful resort to such measures that require interpretation themselves within the context of a wider system and meaning, as the norm is part of the treaty and as such a component of the international tax regime rather than an escape clause from the authority of the regime.

A similarly contentious debate surrounds the future of tax treaty dispute resolution. Chapter 12, by Yariv Brauner, explores the evolution of the soft dispute resolution mechanism that dominates the current regime, known as the mutual agreement procedure, its shortcomings, and the resistance to its reform. This chapter explains the reasons for such resistance, demonstrating that although the most discussed reform-through a complement of mandatory arbitration - seemed to remedy the deficits of the mutual agreement procedure, it has not been widely adopted. The chapter tracks the opposition to tax treaty arbitration, especially among developing countries, to a lack of trust in the international tax regime rather than to arbitration itself. It consequently presents a pathway to arbitration-based reform that should win legitimacy among all countries, including the developing economies.

Complementing these key debates are certain feedback systems that enrich the international tax discourse with external perspectives. Part IV includes four chapters exploring a few of these key feedback systems. One of the most exciting among those is the very recent attention given by political scientists to the international tax regime and tax governance. Chapter 13 provides such a political science perspective of the evolution of the international tax regime. Thomas Rixen and Martin Hearson use in this chapter several theoretical lenses (domestic interests, global power relations, international institutions, and ideas and expertise) to evaluate the evolution of the regime and its governance. Their framework is based on a characterization of the regime by prior work as a policy trilemma for states among the desire to maintain sovereignty, to cooperate with the aim to reduce double taxation, and to coordinate their efforts to fight tax avoidance and evasion. This chapter sheds particular light on the institutional thread that is weaved throughout this Handbook and the reform discourse, especially in terms of reform pace, explaining the various factors that influence the process. This perspective is particularly helpful for legal scholars who often emphasize binary alternatives, analogies, and comparisons rather than balance and dynamics in reform.

Monica Victor and Yariv Brauner, in Chapter 14, discuss the interactions between international tax law and other international economic law regimes, focusing on WTO 
law. This chapter explores the incompatibility of the international tax and trade regimes, and argues that such incompatibility is likely to have more meaningful consequences as more tax-related cases reach the WTO dispute resolution mechanism, a trend that will only be enhanced by the BEPS project and its aftermath. This chapter exposes the most sensitive points of interaction between the regimes through the prism of recent cases that have challenged the dissonance between the regimes. It also demonstrates the weakness of the international tax regime, arguing that it is unlikely to fare better post-BEPS, and points to the institutional informality and illegitimacy of the soft-law-based regime as a key vulnerability, concluding that the regime could benefit from the lessons learned and taught by the more mature trade system in its quest for reform.

A complementary perspective is provided in Chapter 15 by Alice Pirlot, who examines the relationship between international taxation and international environmental law. Pirlot explores different instances in which international tax rules impact or may impact negatively environmental regulation and policy in a world where policies in these two fields are considered almost in complete isolation. Pirlot further analyzes the one area where the two fields interact, namely environmental taxes, elaborating on the potentially positive outcome of global environmental taxes. This pioneering chapter provides for the first time a framework for the coherent study of international tax and environmental policies which promise to dominate many agendas in the coming years.

Chapter 16, by Carlo Garbarino, provides a deep methodological direction for a comparative law analysis of international taxation. This hotly debated methodology suffers from animated disagreements even over its most fundamental properties. Garbarino soberly explains the source of these disagreements as endemic to this feedback system. He argues that there is no unique or unifying method of legal comparative tax research, but different research strategies, which are inspired by underlying competing theoretical conjectures. These strategies are context-based and depend on many variables, so they do not exclude each other and often operate in combination. The purposes of comparative tax studies as well as the objects of comparative tax law vary depending on the research questions asked and the contexts. In light of these difficulties, the chapter provides a plan or a path, itself a methodology, for an effective evaluation of a research project using comparative legal tools in a manner that would also fortify other tools and methods. This path could serve any project without the bias that often characterizes agenda-driven analyses and is therefore fitting of the new global realities faced by the international tax regime.

Finally, Part V directly tackles some of the key questions about the future of the international tax regime. Chapter 17, by Juan Zornoza, examines the transformation of the international tax regime from a regime dominated by bilateral tax treaties with essentially no multilateral legal instruments into a more formal regime infused with multilateral elements. It uses the unique perspective given by the construction, during the BEPS project, of the so-called Multilateral Instrument (MLI), which is effectively the first multilateral tax treaty.

A fundamental factor in the internationalization of the international tax regime has been the dramatic development of its information-exchange mechanisms and particularly the assault on bank secrecy that in a very short time eliminated that long-standing feature of the international economic system. Hugo López López, in Chapter 18, explores a unique facet of the battle for tax transparency-the status of illicitly obtained information - a fundamental legal question that has long been resolved by domestic 
laws, most notably based on the so-called doctrine of the fruits of the poisoned tree. Additionally, the entire subject, including that doctrine, exposes the lack of maturity of the law of taxpayers' rights within the international tax regime, which global expansion necessitates an international law rather than sporadic domestic discussions. The topic of this chapter has been at the top of the agenda of international taxation in recent years as the inevitability of the belated taxpayers' rights discussion has become obvious and in the febrile atmosphere created by sensational "leaks" involving problematic tax information being obtained illicitly by governments of the most powerful economies and made available to other governments, most notably the case of the Lichtenstein data exposed by the German government. López warns of the hazards of a relaxed approach to these violations of fundamental rights. However, he presents the view that perhaps it is not yet time to try and craft a universal rule to deal with similar situations, conservatively preferring to leave the details to each jurisdiction based on its legal and constitutional framework.

Although the core of international tax scholarship, as well as this Handbook, focuses on the taxation of business and entities (corporations in particular), globalization and recent geopolitical developments have elevated the question of human migration to the top of the international political agenda. Mobility of individuals is not a particularly new phenomenon; however, several factors have led to lesser concerns about its international tax treatment. First, there has been a consensus, or at least general preferences for a rather successful set of rules applicable to residence questions. Specifically, the universality of the 183-day residence rules and the tie-breaking rules in Model Article 4 worked well to ensure that a person almost always had a single state of residence for treaty purposes, eliminating concerns of double taxation of mobile individuals. Correspondingly, the residence/source dichotomy dominated the international tax regime making the residence question the most important for these purposes. Moreover, the large majority of cases involved bordering states that for the most part had long-standing domestic law or treaty arrangements to regulate the matter with little conflict. Second, the volume of human mobility and its importance, especially the importance of human capital and high skills, have not (until recently) been sufficiently significant (at least for the countries dominating the international tax regime) and therefore the impact on other states had not made it to the top of the agenda. Third, in the essentially single instance where scholarly treatment of the "Brain Drain" made headlines, the so-called "Bhagwati Tax," it had no actual impact on the international tax regime. Svetislav Kostić, in Chapter 19, demonstrates that circumstances have changed as both the intensity and the importance of migration and brain drain have intensified, and the ability of the states suffering from them to voice their concerns and to impact the future of the international tax regime have become meaningful. This chapter challenges the traditional residence rules and their role in international taxation as unfitting and perhaps unfair and hence illegitimate in the new realities of the twenty-first century. It further proposes a path forward, establishing criteria and clearer purposes for viable reforms, including revival of the Bhagwati Tax proposal, adjusted to the current circumstances.

Last, but not least, Joachim Englisch's chapter explores what is perhaps the most exciting topic in this Handbook (definitely for the non-tax audience): the future taxation of robots. Not only is this chapter focused on non-corporate taxpayers, but it asks whether robots are taxpayers in the first place. The idea emerged together with the increased exposure of the rapid replacement of humans with a robot workforce. This chapter explores 
the various alternatives available for international taxation for taxing this phenomenon, including the taxation of robots as taxpayers, the taxation of the use of robots, and more traditional responses. It raises the little researched matter of integrating a special taxation of robots with existing taxes and fundamental features of the international tax system, such as the arm's length standard. This chapter further exposes the impact of each approach on international tax policy and especially on the core issues of tax competition and the coordination of tax policies among nations. Taxing robots, being so novel, is therefore not only a key issue that the international tax regime will be forced to tackle as an important technological change, but also a fantastic laboratory in which to examine the viability of the foundations of the regime we have in place.

The variety of topics and the different angles of review taken by the fantastic contributors to this volume notwithstanding, the core questions faced by an international tax regime that was designed for the concerns of the richest states a century ago must meet inevitable reform in a very different world of extensive globalization, speedy technological change, and a lack of superpower(s), all of which mandate the organization of norms that could garner universal legitimacy. The purpose of this Handbook is to promote a plurality of approaches and new ideas that could be tested on the path to reform, as it is obvious that, on one hand, the current regime lacks legitimacy and cannot carry on controlling the universe of international taxation as-is, and that, on the other, there is no simple grand plan that could win the day. Hopefully, the ideas and ordered knowledge contained in this Handbook will also assist its readers to come up with more ideas to the benefit of us all. 